Syahrin Suhaimee, Tapsir Serin, Abu Kasim Ali, Nurul Huda Sulaiman and Zulkipli Ghazali

\title{
Public awareness and perception of nanotechnology in Malaysia
}

ABSTRACT. Nanoscience and the concept of nanotechnology have been around since the early 20th century. Since then, several high-impact applications of nanotechnology were seen in electronics, biomedicine, catalysts and aeronautics. Ultimately, it will influence our economy, society and environment. Studies have revealed that about $50 \%$ of the public are aware of nanotechnology, although numerous nanotechnology applications are known to have the potential to be applied in many industries and are currently available in the market. This study found that the level of awareness of nanotechnology among Malaysians is rather low in comparison to the developed countries. Despite the lack of knowledge about nanotechnology among the public in general, existing nanotechnology product users had basic knowledge of nanotechnology, considered that the benefits exceeded the risks and were willing to buy nanotechnology-based products. As knowledge was the most important factor found in this study, educational advertising through the mass media could become a tool to educate and increase awareness among Malaysians. Educating consumers to provide fundamental knowledge of nanotechnology should be the responsibility of the captains of industries, nongovernmental organizations and the Malaysian government alike.

Nanotechnology Perceptions 9 (2013) 198-210

Nonsubscribers: purchase individuai articie 